\title{
Drug holidays: the most frequent type of noncompliance with calcium plus vitamin $D$ supplementation in persistent patients with osteoporosis
}

\author{
This article was published in the following Dove Press journal: \\ Patient Preference and Adherence \\ 16 December 2015 \\ Number of times this article has been viewed
}

\section{Tereza Touskova' \\ Magda Vytrisalova' \\ Vladimir Palicka ${ }^{2}$ \\ Tereza Hendrychova' \\ Leos Fuksa' \\ Radka Holcova' \\ Jana Konopacova' \\ Ales Antonin Kubena \\ 'Department of Social and Clinical Pharmacy, Faculty of Pharmacy in Hradec Kralove, Charles University in Prague, ${ }^{2}$ Osteocentre, Institute of Clinical Biochemistry and Diagnostics, Charles University in Prague, Faculty of Medicine and University Hospital in Hradec Kralove, Hradec Kralove, Czech Republic}

Purpose: All current recommendations include calcium and vitamin D (Ca-D) as an integrated part of osteoporosis treatment. The purpose of this pilot study was to analyze compliance with a fixed combination of $\mathrm{Ca}-\mathrm{D}$ in women persistent with the treatment.

Patients and methods: An observational study was carried out in three osteocenters in the Czech Republic. Women with osteoporosis $\geq 55$ years of age concurrently treated with oral ibandronate were eligible. Compliance was evaluated in a period of 3 months by Medication Event Monitoring System (MEMS), tablet count, and self-report. Nonpersistence was defined as a MEMS-based gap in the use of $\mathrm{Ca}-\mathrm{D}$ to be 30 days or more.

Results: A total of 73 patients were monitored, of which 49 patients were analyzed (target population). Based on MEMS, mean overall compliance was $71 \%$; good compliance ( $\geq 80 \%)$ was observed in $59 \%$ of the patients. As many as $71 \%$ of the patients took drug holidays $(\geq 3$ consecutive days without intake); overall compliance of these patients was $59 \%$ and was slightly lower on Fridays and weekends. Patients without drug holidays were fully compliant (did not omit individual doses). Compliance differed according to daily time at which the patients mostly used the $\mathrm{Ca}-\mathrm{D}$. Afternoon/evening takers showed a mean overall compliance of $82 \%$ while morning/night takers only $51 \%(P=0.049)$. Based on MEMS, tablet count, and self-report, compliance $\geq 75 \%$ was observed in $59 \%, 100 \%$, and $87 \%$ of the patients, respectively. Outcomes obtained by the three methods were not associated with each other. Undesirable concurrent ingestion of $\mathrm{Ca}-\mathrm{D}$ and ibandronate was present only twice.

Conclusion: Despite almost perfect self-reported and tablet count-based compliance, MEMSbased compliance was relatively poor. Consecutive supplementation-free days were common; more than two-thirds of the patients took at least one drug holiday. This pilot study showed drug holiday to be the most important type of noncompliance with $\mathrm{Ca}-\mathrm{D}$ in those who are persistent with the treatment.

Keywords: patient compliance, medication adherence, Medication Event Monitoring System (MEMS), drug holidays, osteoporosis, calcium supplementation, self-report

\section{Introduction}

Osteoporosis is a silent systemic disease characterized by low bone mineral density and microarchitectural deterioration of bone tissue with increased fragility of bones. Osteoporosis and its consequences are a worldwide concern in the current aged society. ${ }^{1}$

A variety of treatments are available to prevent and treat osteoporosis. The bisphosphonates alendronate, ibandronate, risedronate, and zoledronic acid; raloxifene; agents derived from parathyroid hormone; and denosumab and strontium ranelate are most
Correspondence: Magda Vytrisalova Department of Social and Clinical Pharmacy, Faculty of Pharmacy in Hradec Kralove, Charles University in Prague, Heyrovskeho I203, 50005 Hradec Kralove, Czech Republic

Tel +42049506 7648

Fax +42049506 7161

Email vytrm7aa@faf.cuni.cz 
commonly used in Europe. ${ }^{1}$ All current recommendations include calcium and vitamin $\mathrm{D}(\mathrm{Ca}-\mathrm{D})$ as an integrated part of osteoporosis treatment, which determines the success of antiresorptive and osteoanabolic therapy. Intakes of at least $1,000 \mathrm{mg} /$ day of calcium and $800 \mathrm{IU}$ of vitamin D can be recommended in the general management of patients with osteoporosis. ${ }^{1}$

Despite ambiguities regarding the most appropriate supplementation doses and forms of supplements, combined $\mathrm{Ca}-\mathrm{D}$ supplements in a daily dose of $0.5-1.2 \mathrm{~g}$ and 400-800 IU, respectively, are generally recommended in patients receiving bone protective therapy since the evidence for the efficacy of antiresorptives is mostly based on coadministration of $\mathrm{Ca}-\mathrm{D}$ supplements. ${ }^{1-3}$ The use of a fixed combination of $\mathrm{Ca}-\mathrm{D}$ in a single tablet should facilitate treatment adherence, especially if the patient also receives other treatments. ${ }^{3,4}$

Despite the availability of effective pharmacotherapy, approximately $50 \%$ patients with osteoporosis do not adhere to the treatment regimen and/or discontinue the treatment during the first year. ${ }^{1,5,6}$ There is also a high prevalence of $\mathrm{Ca}-\mathrm{D}$ insufficiency in the elderly. ${ }^{7}$ Poor adherence to osteoporosis medication (compliance and persistence) is associated with smaller gains in bone mineral density and a significantly greater risk of fracture. ${ }^{1,8}$ While adherence to bisphosphonates has been extensively studied in common clinical practice, ${ }^{5,6}$ adherence to supplementation therapy escapes attention.

Supplementation with $\mathrm{Ca}-\mathrm{D}$ was associated with a $12 \%$ reduction in the risk of fracture and $24 \%$ reduction in the risk of fracture in a population with a better adherence to the treatment. ${ }^{3}$ However, adherence to supplementation therapy is low even in clinical trials. ${ }^{9}$ Studies on adherence to $\mathrm{Ca}-\mathrm{D}$ therapy in common practice are rare and are limited to persistence, ${ }^{10}$ simple assessment by patient's self-report, ${ }^{11,12}$ or database-based analysis of administrative data which rather reflect co-prescription rate. ${ }^{13}$ In self-reported studies, patient compliance ranges between $30 \%$ and $75 \% .^{11,12,14}$ Determinant factors of adherence to calcium and/or vitamin D treatment were patient's attitude to the treatment, tolerability problems with the treatment, and the number of concurrent drugs. ${ }^{12}$ Only one study ${ }^{14}$ used both objective and subjective methods, but it is limited to women initiating antiresorptive therapy. However, the character of noncompliance has not been studied in detail. Poor timing compliance such as concurrent ingestion of oral bisphosphonate and calcium can lead to adverse interaction resulting in significantly decreased absorption of the bisphosphonate. ${ }^{1}$ We have previously pointed out that compliance with a postdose fasting interval could be a particular problem in patients treated with ibandronate ${ }^{15}$ in which the interval of 60 minutes is twice as long as in other oral bisphosphonates, alendronate and risedronate. Further, taking into account the moderate overestimation of adherence by self-report, ${ }^{16}$ it is important to study if self-reported adherence can be used in common practice to estimate compliance since it is practical, cheap, and suitable to realize in most settings.

The aim of the present analysis was therefore to study compliance with a fixed combination of $\mathrm{Ca}-\mathrm{D}$ in women at risk of fracture who are persistent with such treatment. The primary objective was to study the character of noncompliance. The secondary objectives were to compare compliance obtained from the three methods, Medication Event Monitoring System (MEMS), tablet count, and selfreport, and to study undesirable concurrent ingestion with oral ibandronate.

\section{Methods \\ Study design}

An observational pilot study was performed in consecutive secondary care female patients at risk of osteoporosis-related fracture.

\section{Setting}

Study participants were recruited from three outpatient osteocenters providing specialized care to patients with osteoporosis in the Czech Republic from May 2013 to October 2014. The osteoporosis centers were units of the following hospitals: University Hospital in Hradec Kralove, Institute of Rheumatology Prague, and Pardubice Regional Hospital.

\section{Duration of the study}

Patients were monitored for 3 months.

\section{Participants}

All patients fulfilling the eligibility criteria were asked to participate in the study. The inclusion criteria were as follows:

- postmenopausal woman older than 55 years;

- diagnosis of osteoporosis (measured by dual energy X-ray absorptiometry, bone mineral density measurement, $\mathrm{T}$-score $\leq-2.5$ in the lumbar spine and/or hip region);

- current treatment of osteoporosis with oral ibandronate;

- treatment with oral bisphosphonate in an osteocenter for at least 2 years;

- supplementation with a fixed combination of Ca-D, preparation Caltrate $600 \mathrm{mg} / 400 \mathrm{IU}$ of vitamin D3 (start or continuation with the preparation). Only patients indicated for the calcium supplementation at the dose contained in one tablet, that is, $600 \mathrm{mg}$ of calcium a day, were eligible. 
Exclusion criteria were as follows:

- use of a drug dispenser;

- failure to adhere to the study protocol;

- noninitiation with the Ca-D treatment;

- nonpersistence with the Ca-D treatment.

These patients were not the target population of the study and were intended to be excluded from the analysis.

\section{Outcome measures}

In osteoporosis field, the term adherence is understood as both compliance (proximity to treatment recommendation often simplified as the number of doses taken divided by the number of prescribed doses) and persistence (how long the medication is taken). ${ }^{1,17}$ Based on this concept, we studied compliance-related outcomes in persistent patients. Based on MEMS data, nonpersistence was defined as a gap in the use of $\mathrm{Ca}-\mathrm{D}$ to be 30 days or more. ${ }^{18,19}$

\section{Primary outcome}

The primary outcome was the character of noncompliance which was studied using MEMS. The MEMS is an electronic monitoring device intended for providing records on dosing history of drugs. The MEMS container consists of a bottle and a cap with a microprocessor. The cap registers the date and time of each opening of the container. The MEMSbased measures were adopted from literature and (if needed) adjusted to our scenario..$^{20-23}$

- Overall compliance: ratio of the number of container openings to the number of prescribed doses. The overall compliance can exceed $100 \%$.

- Correct dosing (days with correct number of doses, ie, one a day): percentage of the treatment days with one container opening. The correct dosing can reach a maximum of $100 \%$.

- Variability in time of drug intake: Ca-D was used in a regular time interval if $75 \%$ or more doses were used in the same time period, that is, regular takers. Among regular takers, we defined four categories. Morning takers took more than $75 \%$ of doses between 6 am and 12 am, afternoon takers between 12 am and 6 pm, evening takers between $6 \mathrm{pm}$ and $12 \mathrm{pm}$, and night takers between $12 \mathrm{pm}$ and $6 \mathrm{am}$. Participants who could not be classified as regular takers were referred to as variable takers.

- Single or sequentially missed multiple dose ${ }^{21}$ were classified as omissions of a dose on a single day, 2 consecutive days, and drug holidays. We defined the omission of a dose on a single day ( 24 hours) as $\mathrm{Ca}-\mathrm{D}$-free interval from 3 am to $3 \mathrm{pm}$. A similar rule was used to define the omission of more than 1 day (Figure 1).

- Drug holidays were defined as a sequence of at least 3 consecutive days without taking the drug.

\section{Secondary outcomes}

We compared compliance (proportion of doses taken) using MEMS, tablet count, and patient's self-report. Further, we examined potential concurrent ingestion of ibandronate and $\mathrm{Ca}-\mathrm{D}$.

\section{Tablet count}

After returning the MEMS container, the remaining tablets were counted by the researchers. Tablet count was defined as the number of tablets taken (not present in the container) expressed as the percentage of the correct number of tablets advised by the physician for the study period, that is, 90 tablets. $^{24,25}$

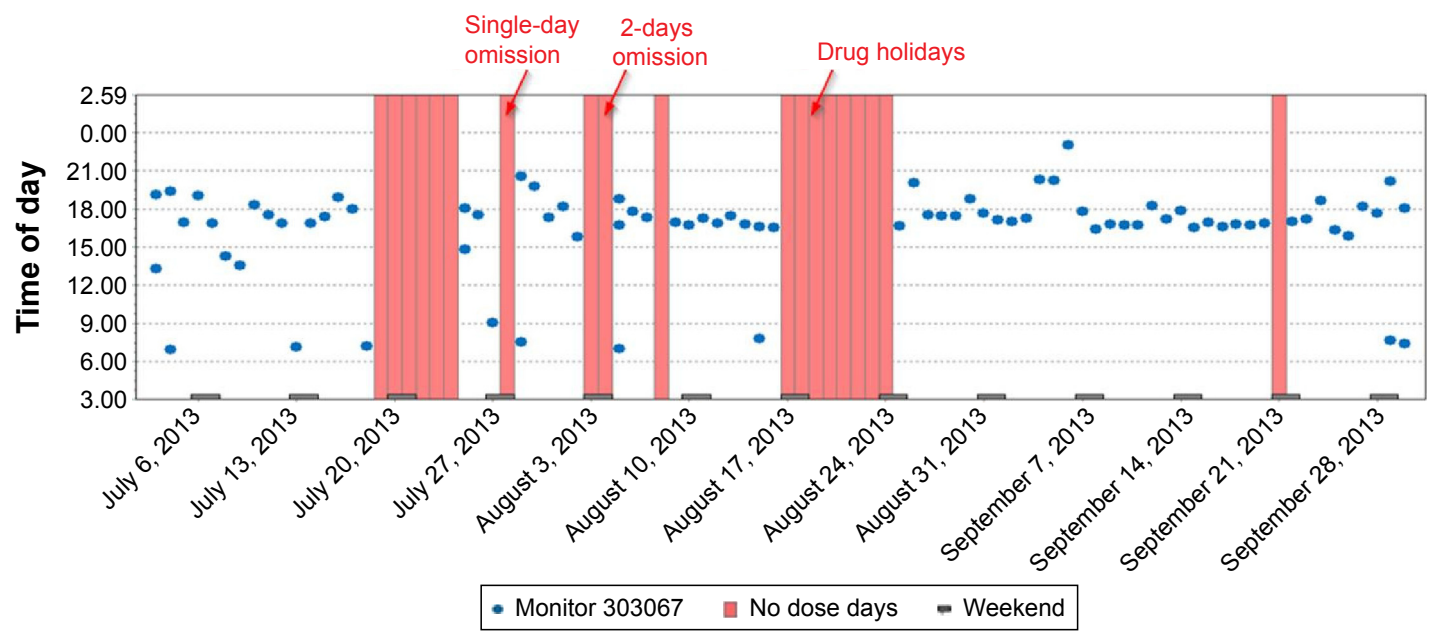

Figure I Medication Event Monitoring System-based record of drug use in a particular patient covering a period of 3 months. Note: Dots indicate container openings, and columns indicate days without container opening. 


\section{Self-report}

Patients responded the following questions in a one-page questionnaire:

- How often did you take the Caltrate formula in the last 3 months? Response alternatives were: very often (more than $75 \%$ of the days), often ( $51 \%-75 \%$ of the days), sometimes ( $25 \%-50 \%$ of the days), and rarely or not at all (less than $25 \%$ of the days).

- How many times did you miss a dose of Caltrate in the last month? (Open question).

Besides the questions on adherence, the questionnaire included also questions on the handling of the MEMS container, calcium-related gastrointestinal disorders, and the knowledge of the recommended daily intake of calcium.

\section{Concurrent ingestion of $\mathrm{Ca}-\mathrm{D}$ with ibandronate}

Oral ibandronate should be taken after an overnight fast and 1 hour before the first food or drink (other than water) of the day or any other oral drugs or supplementation (including calcium). Calcium supplements are likely to interfere with the absorption of ibandronate. Therefore, patients should not take other oral drugs for 1 hour following the intake of ibandronate. The evaluation of concurrent ingestion of ibandronate and $\mathrm{Ca}-\mathrm{D}$ was based on MEMS time of the use of $\mathrm{Ca}-\mathrm{D}$ and self-reported time of ibandronate use recorded in the calendar. The concurrent ingestion was defined as use of $\mathrm{Ca}-\mathrm{D}$ within 1 hour after the use of ibandronate.

\section{Procedure}

At baseline, each patient got a MEMS bottle containing 90 tablets of Ca-D (amount for 3 month-treatment) and a simple calendar for recording the use of oral ibandronate (the date and time of each use). All patients were instructed to take one tablet each day directly from the package and to bring the container with the rest of the tablets at the next visit. The day after the baseline visit, the patients started to be monitored.

At the check-up 3 months later, the patients returned the MEMS container, the calendar, and completed the short questionnaire. One day before the check-up visit, researchers sent a telephone reminder.

\section{Data processing and statistical analysis}

Data from the MEMS were transferred into a computer at the end of the study periods and processed using the PowerView 3.5.1 program (Aardex, Zug, Switzerland). All recorded container openings were considered to represent a single dose event. ${ }^{26}$

Most variables did not follow a normal distribution and therefore nonparametric statistics were applied. The associations between variables were assessed using the following tests:

1. Kendall correlations for two continuous (ordinal) variables.

2. Mann-Whitney test for dichotomous and continuous (ordinal) variables.

Statistical analyses were calculated using PASW software (version 18.0). $P<0.05$ was considered statistically significant.

\section{Ethics}

The study protocol was approved by the ethical committees of the respective hospitals. Informed consent was required from all participants. Neither physicians nor patients were informed about individual study outcomes.

\section{Results Study population}

Five patients refused participation in the study. A total of 73 patients ( $94 \%$ of the target population) were recruited and monitored. As many as 24 patients were excluded due to prespecified exclusion criteria (Figure 2), and 49 patients were available for the analysis.

Basic characteristics of the studied population are summarized in Table 1.

\section{Character of noncompliance}

No multiple openings within a period of $\leq 15$ minutes were observed. The overall compliance was $71 \%$ and the other compliance-related outcomes based on MEMS are summarized in Table 2. Characteristics of dosing omissions are presented in Figure 3.

Patients without drug holidays were fully compliant (overall compliance was 101\%), which means they practically did not omit doses. Overall compliance in patients with drug holidays was $59 \%$ and was slightly lower on Fridays and on weekends (Figure 4).

Periodic patterns in the execution of a dosing regimen were also analyzed. Overall compliance differed according to the daily time during which patients mostly used the drug (in $75 \%$ of cases or more). The subgroup of afternoon/evening takers $(\mathrm{N}=4 / 17)$ showed a mean overall compliance of $82 \%$ while the subgroup of morning/night takers $(\mathrm{N}=10 / 0)$ only 


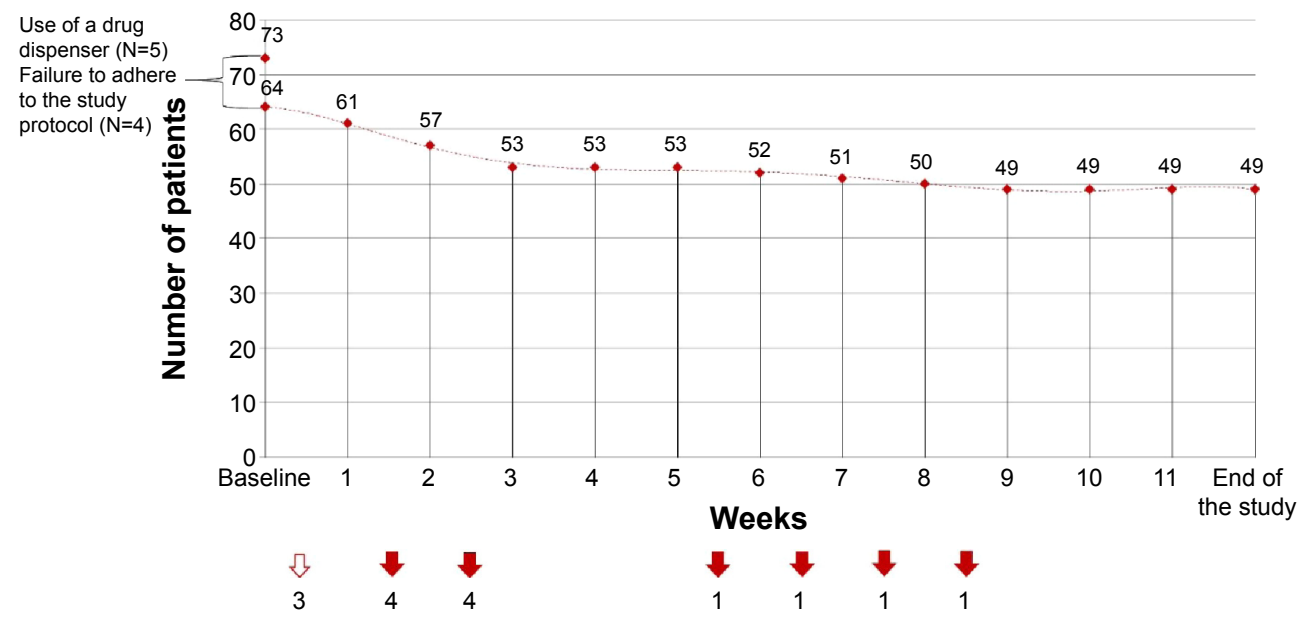

Figure 2 Patients excluded from the study and reasons for their exclusion.

Notes: The white arrow indicates patients who did not initiate the treatment (noninitiation) and the red arrows indicate patients who were nonpersistent with the treatment (discontinuation within the study period).

$51 \%(P=0.049)$. Mean overall compliance in variable takers $(\mathrm{N}=18)$ was $70 \%$ (Figure 5 ).

\section{Comparison of compliance using MEMS, tablet count, and self-report}

Categories of overall compliance based on the three methods in the whole study period are compared in Figure 6. Mean overall compliance in the last month of the study was $72 \%$ and $97 \%$ when using MEMS and self-report, respectively. Compliance-related outcomes derived from the three methods were not associated with each other.

\section{Concurrent ingestion of ibandronate and Ca-D}

The concurrent ingestion was recorded only in two patients, once in each patient.

Table I Characteristics of the study population $(\mathrm{N}=49)$

\begin{tabular}{ll}
\hline Age (years) & $\mathrm{N}=49$ \\
Mean; median (minimum-maximum) & $70.5 ; 70.0$ (56-86) \\
How many prescription drugs do you currently take? & $\mathrm{N}=40$ \\
$\begin{array}{l}\text { Mean; median (minimum-maximum) } \\
\text { Do you know what your target recommended daily }\end{array}$ & $4.7 ; 5.0(0-10)$ \\
$\begin{array}{l}\text { intake of calcium is? } \\
\text { Yes; Yes together with a statement of the correct }\end{array}$ & $47.9 ; 29.0$ \\
$\begin{array}{l}\text { answer (\%) } \\
\text { No (\%) }\end{array}$ & 52.1 \\
$\begin{array}{l}\text { How many calcium formulas have you tried? } \\
\text { Mean; median (minimum-maximum) }\end{array}$ & $\mathrm{N}=47$ \\
$\begin{array}{l}\text { Do calcium formulas cause gastrointestinal disorders } \\
\text { in you? }\end{array}$ & $2.1 ; 2.0(0-6)$ \\
Yes (\%) & \\
\hline
\end{tabular}

Note: N, Number of valid responses to each item.

\section{Discussion}

This was a 3-month prospective study on electronically monitored compliance with osteoporosis supplementation therapy with retrospective self-evaluation of the compliance. The study was designed to be very close to common clinical practice and was focused on compliance with fixed combination of $\mathrm{Ca}-\mathrm{D}$ in persistent female patients only. Despite almost perfect self-reported and tablet count-based compliance, MEMS-based compliance was relatively poor, which stresses the importance of objective methods in the measurement of compliance. Compliance better than $80 \%$, often referred as cut point of good compliance, ${ }^{5}$ was achieved

Table 2 Compliance-related outcomes based on Medication Event Monitoring System ( $\mathrm{N}=49)$

\begin{tabular}{|c|c|}
\hline Overall compliance (\%) & $71.0 ; 84.4(3-107)$ \\
\hline \multicolumn{2}{|l|}{ Mean; median (minimum-maximum) } \\
\hline Overall compliance in the first month (\%) & $74.8 ; 96.7(3-117)$ \\
\hline \multicolumn{2}{|l|}{ Mean; median (minimum-maximum) } \\
\hline Overall compliance in the second month (\%) & $66.7 ; 80.0(3-103)$ \\
\hline \multicolumn{2}{|l|}{ Mean; median (minimum-maximum) } \\
\hline Overall compliance in the third month (\%) & $71.6 ; 86.7(3-107)$ \\
\hline \multicolumn{2}{|l|}{ Mean; median (minimum-maximum) } \\
\hline Overall compliance $\geq \mathbf{8 0} \%, \%$ of patients & 59.2 \\
\hline Overall compliance $\geq 75 \%$, $\%$ of patients & 59.2 \\
\hline Overall compliance $\geq 67 \%$, $\%$ of patients & 69.4 \\
\hline Correct dosing (\%) & $63.0 ; 73.0(3-98)$ \\
\hline \multicolumn{2}{|l|}{ Mean; median (minimum-maximum) } \\
\hline Presence of drug holidays, \% of patients & 71.4 \\
\hline Longest drug holidays - number of days & $10.7 ; 8.0(3-29)$ \\
\hline \multicolumn{2}{|l|}{ Mean; median (minimum-maximum) } \\
\hline Drug holidays longer than 7 days, $\%$ of patients & 42.9 \\
\hline
\end{tabular}

Note: Drug holidays, a sequence of at least 3 consecutive days without taking the drug. 


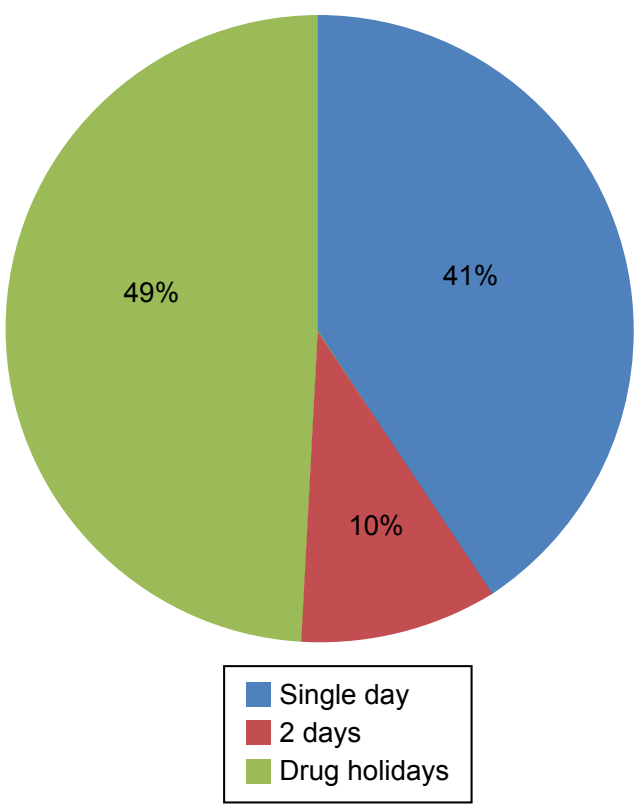

Figure 3 Omitted doses within single-day omission, 2-day omission, and drug holidays (\%); all omitted doses represent 100\%.

Note: Drug holidays, a sequence of at least 3 consecutive days without taking the drug.

in $60 \%$ of participants only. This number seems particularly low in the light of the fact that the study focused specifically on the implementation component of compliance; noninitiation and early discontinuation which can further decrease adherence to the treatment were not studied. ${ }^{20}$ More than two-thirds of patients took at least one drug holiday (3 or

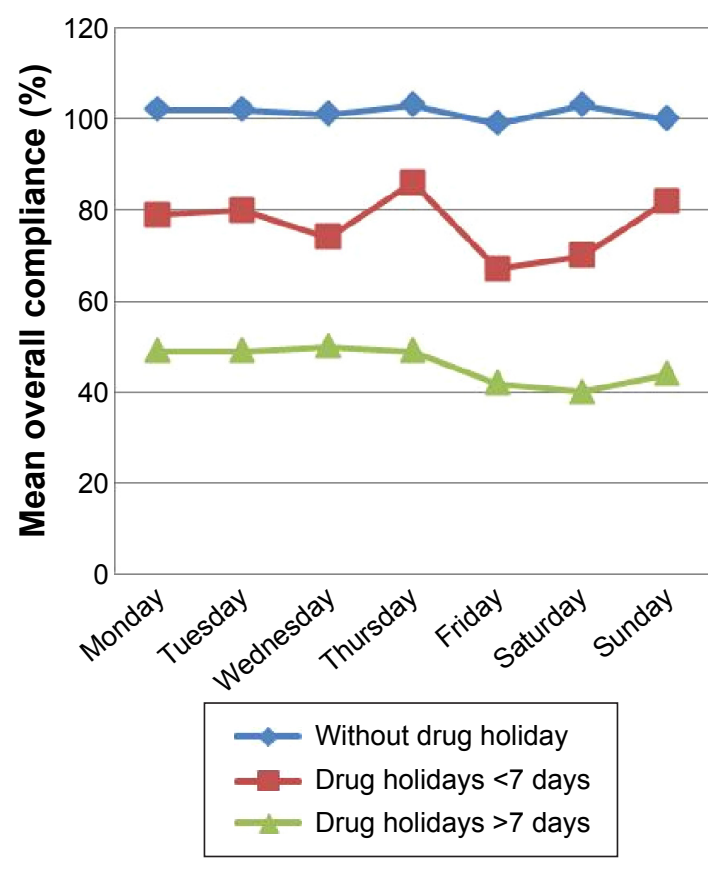

Figure 4 Mean overall compliance according to presence of drug holidays at individual weekdays and weekends (\%).

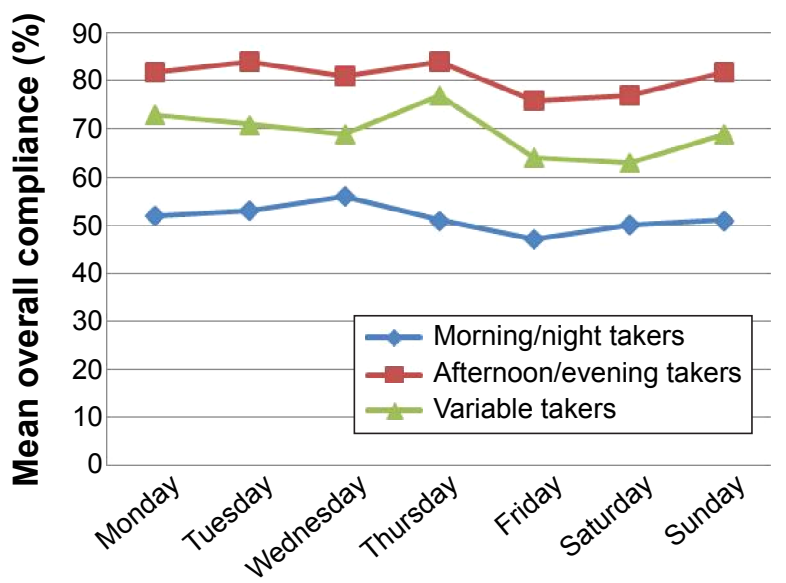

Figure $\mathbf{5}$ Mean overall compliance according to the category of takers at individual weekdays and weekends.

more consecutive days without intake) and 43\% took drug holiday longer than a week. This shows the implementation of the dosing regimen, that is, habit of taking once daily one tablet is not fixed well in most participants. About half of all dose-free days were part of drug holidays. These findings made drug holidays a leading problem in compliance with $\mathrm{Ca}-\mathrm{D}$ in persistent patients in our pilot study. Bioavailability of oral ibandronate is reduced in the presence of calcium which interferes with absorption of ibandronate. Patients are probably very well informed and aware of this since undesirable concurrent ingestion of ibandronate and $\mathrm{Ca}-\mathrm{D}$, which can cause an interaction and potentially decrease the effect of ibandronate, was rare.

To our knowledge, this is the first study in which patient compliance with $\mathrm{Ca}-\mathrm{D}$ was evaluated by a combination of both objective and subjective methods. Electronic medication-event monitoring which consists of automatic compilation of the time history of each patient's entry into the drug package has been considered to provide the most reliable data on compliance. ${ }^{27}$ However, it is relatively expensive and difficult to be used in common clinical practice. Therefore, methods that correlate with MEMS and are easier to perform can be of great importance for clinical practice.

However, appropriateness of the use of questionnaire instruments is sometimes questionable. The differentiation between an effect indicator model (all items in an instrument measure the same construct) and causal indicator model (the items measure unique, additive components of adherence) is crucial. Current multi-item tools, that is, validated questionnaires, can raise a question on what is actually measured (adherence only or a mixture of adherence, attitudes to the treatment, beliefs, preferences, and intentions). ${ }^{28}$ Our particular interest was to formulate simple questions which 


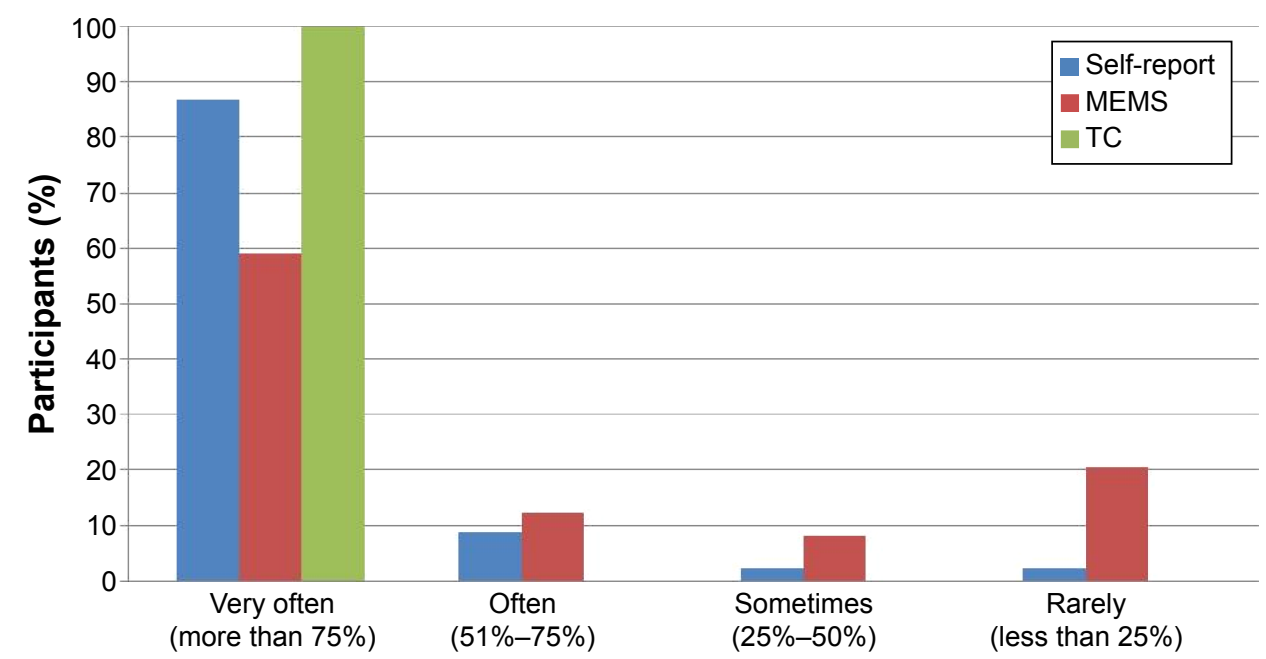

Figure 6 Categories of overall compliance with calcium/vitamin D supplementation in the cohort of 49 participants in the whole study period (3 months). Abbreviations: MEMS, Medication Event Monitoring System; TC, tablet count.

express exactly the same measure as MEMS, that is, behavior (not intentions or attitudes) and omission of doses in the study period. Our questionnaire besides other items contained two simple questions on compliance with four response alternatives to avoid central tendency.

Discrepancy between MEMS and the other methods (the self-evaluation and tablet count) raises considerations regarding bias. Self-reported questionnaires usually overestimate adherence. Based on works of Shi et al, ${ }^{16,29}$ self-report compared to MEMS overestimates adherence by $10 \%-20 \%$, but the methods are at least moderately correlated with each other. ${ }^{16,24}$ The over-reporting is generally attributed to social desirability bias and poor recall (for forgotten events). However, our difference between MEMS and other methods used (self-report and tablet count) is even higher, more than $25 \%$. This can be explained as follows: 1) social desirability bias regarding selfreport and tablet count is larger than in other similar studies and 2) MEMS measurement was free of Hawthorne bias.

1. Most studies comparing MEMS and self-report are from the USA or focused on the treatment of HIV. ${ }^{16,29}$ Social desirability bias can vary according to the setting, health care system, and cultural background. It could be more remarkable in post-communist countries and associated with perceived paternalism in medical decision making. Our present findings are in accordance with former Czech studies evaluating patient compliance with chronic conditions directly at clinics. Despite anonymity of the respondent, self-reported quantitative compliance (questions on doses used or missed) was almost always very high. ${ }^{15,30-32}$ Social desirability is probably the dominant reason why our participants not only overrated their compliance by the questionnaire, but also spilled tablets out of MEMS and returned empty containers in most cases.

2. Hawthorne effect refers to those patients who overestimate their adherence when they know they are monitored. ${ }^{33}$ This is apparent in the study on compliance with cardiovascular medication; correct dosing was $77 \%$ versus $59 \%$ in patients with and without information on the purpose of the electronic pillbox, respectively. ${ }^{34}$ In most MEMS-based studies, participants were informed they are electronically monitored on medication adherence. . $3,24,34,35^{2}$ MEMS-based adherence in most of these studies was relatively close to self-reported adherence. ${ }^{16,23,24} \mathrm{We}$ did not arouse the impression of electronically-mediated monitoring of compliance, so we believe the Hawthorne effect was practically absent in our study. Two studies in which monitoring of adherence was not suspected ${ }^{34,35}$ also found out larger difference between MEMS-based and self-reported adherence; correct dosing of $59 \%$ versus $79 \%{ }^{34}$ and $90 \%$ versus $100 \%,{ }^{35}$ respectively.

Our almost perfect self-reported and tablet count-based compliance resulted in the uniformity of the respective variables; therefore, the impact of correlation, which showed no relationship among the methods, was weak.

The question remains how to easily and accurately estimate quantitative compliance in common practice. Social desirability seems to be a leading problem even in anonymous questionnaires completed directly at clinics.

In most MEMS-based studies on chronic treatment, patient compliance was higher ${ }^{16,23,24,34}$ than in our study. In a few studies, compliance was lower. ${ }^{16,34}$ Nevertheless, our study included persistent patients only. 
In the study by Vrijens et al, ${ }^{21}$ almost 5,000 hypertensive patients were monitored for 12 months. As much as $43 \%$ of doses were omitted within drug holidays. Our participants possibly considered their treatment less important, like supplementary therapy, and therefore even more, half of all doses, were omitted within drug holidays. As observed in the study on adherence with mesalazine in patients with ulcerative colitis, ${ }^{24}$ our adherence was slightly higher before the check-up visit in the third month compared to the second.

In MEMS-based studies, lower adherence to longterm treatment is observed on weekends and possibly on Fridays. ${ }^{21,24,26}$ In our study, slightly lower overall compliance was also observed on Fridays and Saturdays. We suppose that Fridays do not fit into the common daily routine, but Sundays $\mathrm{do}$, because the patients used $\mathrm{Ca}-\mathrm{D}$ in the afternoon/evening based on their physician's recommendation.

Patients are usually instructed to use the $\mathrm{Ca}-\mathrm{D}$ supplementation in the afternoon or evening by a prescribing physician. Our MEMS-based data are in accordance with the recommendation. Almost a half of patients used the supplementation mostly at this daily time; this subgroup, not surprisingly, showed better overall compliance. Similarly, considering the fact that antihypertensives are mostly recommended to be used in the morning, morning takers were most compliant with their treatment in the above mentioned study on adherence in patients with hypertension. ${ }^{21}$

Our pilot study was relatively small, limited by the effort to capture as much homogeneous sample of patients as possible. To limit potential bias, we tried to keep the "naturalistic" character, that is, to organize the study in a way that is as much close to common clinical routine as possible.

Although it is still possible that patients did open the cap but did not actually take their medication, the MEMS may be less vulnerable to social desirability particularly when patients do not suspect they are monitored.

As the participants were recruited directly from the osteocenters, they may be more motivated to cooperate with physicians. The participants are likely to comply better with the treatment regimen than those who refuse participation in studies; therefore, patient compliance could be even slightly overestimated. Further, the participants were recruited from large osteocenters where the most specialized care and intensive counseling is provided.

\section{Conclusion}

Good compliance with a fixed combination of $\mathrm{Ca}-\mathrm{D}$ was observed in $60 \%$ of persistent participants; consecutive supplementation-free days were common making drug holidays the most important type of noncompliance in our pilot study. In common clinical practice, emphasis should be placed on adequate support of compliance and ensuring the recommended daily intake of $\mathrm{Ca}-\mathrm{D}$ in patients at risk of osteoporotic fracture. Self-reported evaluation of missed doses was highly overestimated and did not provide a real picture of patient compliance. A larger study is needed to confirm these preliminary findings.

\section{Acknowledgments}

We are grateful to Dr Bernard Vrijens for consultation on electronically-compiled dosing histories and sharing his profound, wide-ranging experience in medication adherence research. The authors would like to thank the physicians for patient recruitment: Prof Karel Pavelka, MUDr Olga Ruzickova, and MUDr Tomas Hala; further, thanks to Prof Jiri Vlcek for support of the MEMS method, Vera Holkova who assisted in study organization and data collection, and Mgr Michal Urbanek for English editing. The study was supported by Charles University in Prague, project SVV 260 187, and Program MH CZ - DRO (UHHK, 00179906).

\section{Disclosure}

The authors report no conflicts of interest in this work.

\section{References}

1. Kanis JA, McCloskey EV, Johansson H, Cooper C, Rizzoli R, Reginster JY. European guidance for the diagnosis and management of osteoporosis in postmenopausal women. Osteoporos Int. 2013; 24(1):23-57.

2. Strom O, Borgstrom F, Kanis JA, et al. Osteoporosis: burden, health care provision and opportunities in the EU. A report prepared in collaboration with the International Osteoporosis Foundation (IOF) and the European Federation of Pharmaceutical Industry Associations (EFPIA). Arch Osteoporos. 2011;6(1-2):59-155.

3. Tang BM, Eslick GD, Nowson GD, Smith C, Bensoussan A. Use of calcium in combination with vitamin $\mathrm{D}$ supplementation to prevent fractures and bone loss in people aged 50 years or older: a meta-analysis. Lancet. 2007;370:657-666.

4. Bangalore S, Kamalakkannan G, Parkar S, Messerli FH. Fixed-dose combinations improve medication compliance: a meta-analysis. Am JMed. 2007; 120(8):713-719.

5. Cramer JA, Gold DT, Silverman SL, Lewiecki EM. A systematic review of persistence and compliance with bisphosphonates for osteoporosis. Osteoporos Int. 2007;18(8):1023-1031.

6. Kothawala P, Badamgarav E, Ryu S, et al. Systematic review and metaanalysis of real-world adherence to drug therapy for osteoporosis. Mayo Clin Proc. 2007;82:1493-1501.

7. Bruyère $O$, Malaise $O$, Neuprez A, Collette J, Reginster JY. Prevalence of vitamin D inadequacy in European postmenopausal women. Curr Med Res Opin. 2007;23:1939-1944.

8. Ross S, Samuels E, Gairy K, Iqbal S, Badamgarav E, Siris E. A metaanalysis of osteoporotic fracture risk with medication nonadherence. Value Health. 2011;14:571-581. 
9. Brunner R, Dunbar-Jacob J, Leboff MS, et al. Predictors of adherence in the women's health initiative calcium and vitamin D trial. Behav Med. 2009;34(4):145-155.

10. Giusti A1, Barone A, Razzano M, et al. Persistence with calcium and vitamin D in elderly patients after hip fracture. J Bone Miner Metab. 2009;27(1):95-100.

11. Castelo-Branco C, Cortés X, Ferrer M. Treatment persistence and compliance with a combination of calcium and vitamin D. Climacteric. 2010; 13(6):578-584.

12. Sanfelix-Genovés J, Gil-Guillén VF, Orozco-Beltran D, et al. Determinant factors of osteoporosis patients' reported therapeutic adherence to calcium and/or vitamin D supplements: a cross-sectional, observational study of postmenopausal women. Drugs Aging. 2009; 26(10):861-869.

13. Reymondier A, Caillet P, Abbas-Chorfa F, et al. MENOPOST calcium and vitamin D supplementation in postmenopausal osteoporosis treatment: a descriptive cohort study. Osteoporos Int. 2013; 24(2):559-566.

14. Díez A, Carbonell C, Calaf J, Caloto MT, Nocea G. Observational study of treatment compliance in women initiating antiresorptive therapy with or without calcium and vitamin D supplements in Spain. Menopause. 2012;19(1):89-95.

15. Vytrisalova M, Touskova T, Ladova K, et al. Adherence to oral bisphosphonates: 30 more minutes in dosing instructions matter. Climacteric. 2015;18:1-9.

16. Shi L, Liu J, Fonseca V, Walker P, Kalsekar A, Pawaskar M. Correlation between adherence rates measured by MEMS and self-reported questionnaires: a meta-analysis. Health Qual Life Outcomes. 2010; 8(1):99.

17. Dezii CM. Persistence with drug therapy: a practical approach using administrative claims data. Manag Care. 2001;10:42-45.

18. Schousboe JT, Dowd BE, Davison ML, Kane RL. Association of medication attitudes with non-persistence and non-compliance with medication to prevent fractures. Osteoporos Int. 2010;21:1899-1909.

19. Hadji P, Claus V, Ziller V, Intorcia M, Kostev K, Steinle T. GRAND: the German retrospective cohort analysis on compliance and persistence and the associated risk of fractures in osteoporotic women treated with oral bisphosphonates. Osteoporos Int. 2012;23:223-231.

20. Vrijens B, De Geest S, Hughes DA, et al. A new taxonomy for describing and defining adherence to medications. Br J Clin Pharmacol. 2012; 73(5):691-705.

21. Vrijens B, Vincze G, Kristanto P, Urquhart J, Burnier M. Adherence to prescribed antihypertensive drug treatments: longitudinal study of electronically compiled dosing histories. BMJ. 2008;336(7653): 1114-1117.

22. Kardas P. Compliance, clinical outcome, and quality of life of patients with stable angina pectoris receiving once-daily betaxolol versus twice daily metoprolol: a randomized controlled trial. Vasc Health Risk Manag. 2007;3:235-242.
23. Zeller A, Schroeder K, Peters TJ. An adherence self-report questionnaire facilitated the differentiation between nonadherence and nonresponse to antihypertensive treatment. J Clin Epidemiol. 2008;61(3):282-288.

24. Gillespie D, Hood K, Farewell D, Stenson R, Probert C, Hawthorne AB. Electronic monitoring of medication adherence in a 1-year clinical study of 2 dosing regimens of mesalazine for adults in remission with ulcerative colitis. Inflamm Bowel Dis. 2014;20(1):82-91.

25. Finigan J, Naylor K, Paggiosi MA, Peel NF, Eastell R. Adherence to raloxifene therapy: assessment methods and relationship with efficacy. Osteoporos Int. 2013;24(11):2879-2886.

26. Cals JW, Hopstaken RM, Le Doux PH, Driessen GA, Nelemans PJ, Dinant GJ. Dose timing and patient compliance with two antibiotic treatment regimens for lower respiratory tract infections in primary care. Int J Antimicrob Agents. 2008;31(6):531-536.

27. Osterberg L, Blasche T. Adherence to medication. NEngl J Med. 2005; 353(5):487-497.

28. Voils CI, Hoyle RH, Thorpe CT, Maciejewski ML, Yancy WS Jr. Improving the measurement of self-reported medication nonadherence. $J$ Clin Epidemiol. 2011;64:250-254.

29. Shi L, Liu J, Koleva Y, Fonseca V, Kalsekar A, Pawaskar M. Concordance of adherence measurement using self-reported adherence questionnaires and medication monitoring devices. Pharmacoeconomics. 2010; 28(12):1097-1107.

30. Hendrychova T, Vytrisalova M, Smahelova A, Vlcek J, Kubena AA. Adherence in adults with type 1 diabetes mellitus correlates with treatment satisfaction but not with adverse events. Patient Prefer Adherence. 2013; 7:867-876.

31. Vytrisalova M, Blazkova S, Palicka V, et al. Self-reported compliance with osteoporosis medication - qualitative aspects and correlates. Maturitas. 2008;60(3):223-229.

32. Ladova K, Matoulkova P, Zadak Z, et al. Self-reported adherence by MARS-CZ reflects LDL cholesterol goal achievement among statin users: validation study in the Czech Republic. J Eval Clin Pract. 2014; 20(5):671-677.

33. McCambridge J, Witton J, Elbourne DR. Systematic review of the Hawthorne effect: new concepts are needed to study research participation effects. J Clin Epidemiol. 2014;67(3):267-277.

34. Zeller A, Ramseier E, Teagtmeyer A, Battegay E. Patients' self-reported adherence to cardiovascular medication using electronic monitors as comparators. Hypertension Res. 2008;31(11):2037-2043.

35. Nieuwenhuis MM, Jaarsma T, van Veldhuisen DJ, van der Wal MH Self-reported versus 'true' adherence in heart failure patients: a study using the medication event monitoring system. Neth Heart J. 2012;20(7-8):313-319.
Patient Preference and Adherence

\section{Publish your work in this journal}

Patient Preference and Adherence is an international, peer-reviewed, open access journal that focuses on the growing importance of patient preference and adherence throughout the therapeutic continuum. Patient satisfaction, acceptability, quality of life, compliance, persistence and their role in developing new therapeutic modalities and compounds to optimize

\section{Dovepress}

clinical outcomes for existing disease states are major areas of interest for the journal. This journal has been accepted for indexing on PubMed Central. The manuscript management system is completely online and includes a very quick and fair peer-review system, which is all easy to use. Visit http://www. dovepress.com/testimonials.php to read real quotes from published authors. 